\title{
THE MATERIALS ON INTERNATIONAL SPACE STATION EXPERIMENT (MISSE): FIRST RESULTS FROM MSFC INVESTIGATIONS
}

\author{
Miria Finckenor* \\ Mail Code EM50 \\ Marshall Space Flight Center, AL 35812 \\ miria.finckenor@nasa.gov
}

\begin{abstract}
Marshall Space Flight Center worked with the Air Force Research Laboratory, Naval Research Laboratory, Langley Research Center, Glenn Research Center, the Jet Propulsion Laboratory, Johnson Space Center, Boeing, Lockheed Martin, TRW, the Aerospace Corporation, Triton Systems, AZ Technology, Alion (formerly IITRI), ENTECH, and L'Garde to bring together the first external materials exposure experiment on International Space Station (ISS). MISSE re-uses hardware from the MEEP flown on the Russian space station Mir. MISSE has returned a treasure trove of materials data that will be useful not only for ISS but also for programs as diverse as the new Crew Exploration Vehicle, the James Webb Telescope, the Lunar Surface Access Module, the Robotic Lunar Exploration Program, High Altitude Airships, and solar sails.

MISSE-1 and -2 (Figure 1) were attached to the Quest airlock on ISS for 4 years and were retrieved during STS-114. MISSE-3 and -4 were bumped from STS-114 and are currently slated for deployment during STS-121. MISSE-5 (Figure 2) was deployed during STS-114.
\end{abstract}

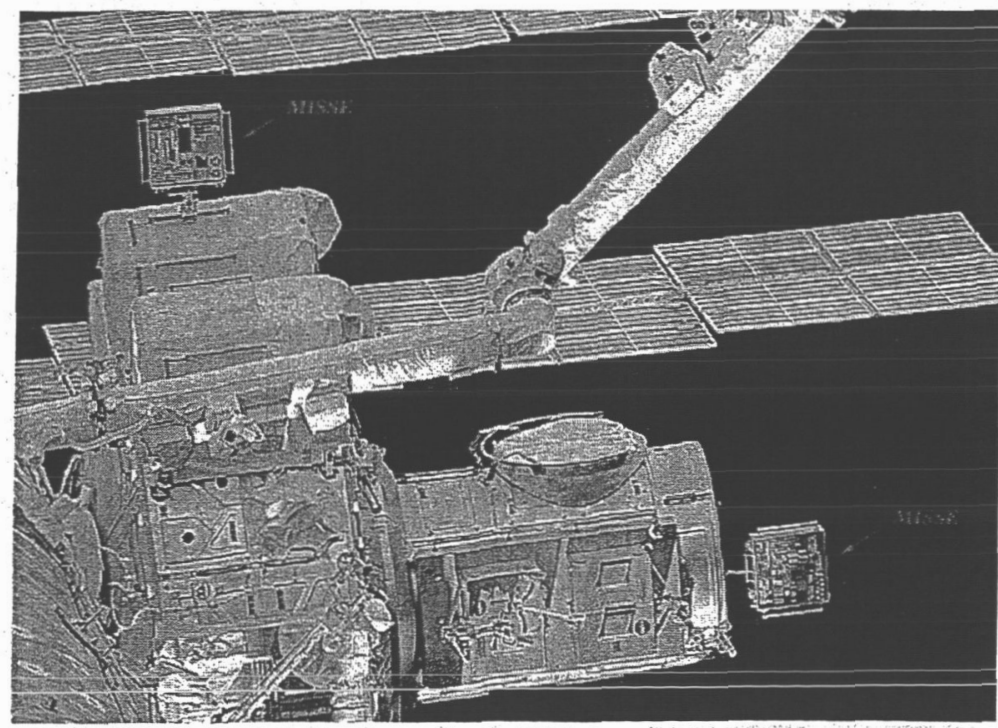

Figure 1. MISSE-1 and -2 deployed on ISS from August 2001 to August 2005

- Associate Fellow, AIAA 


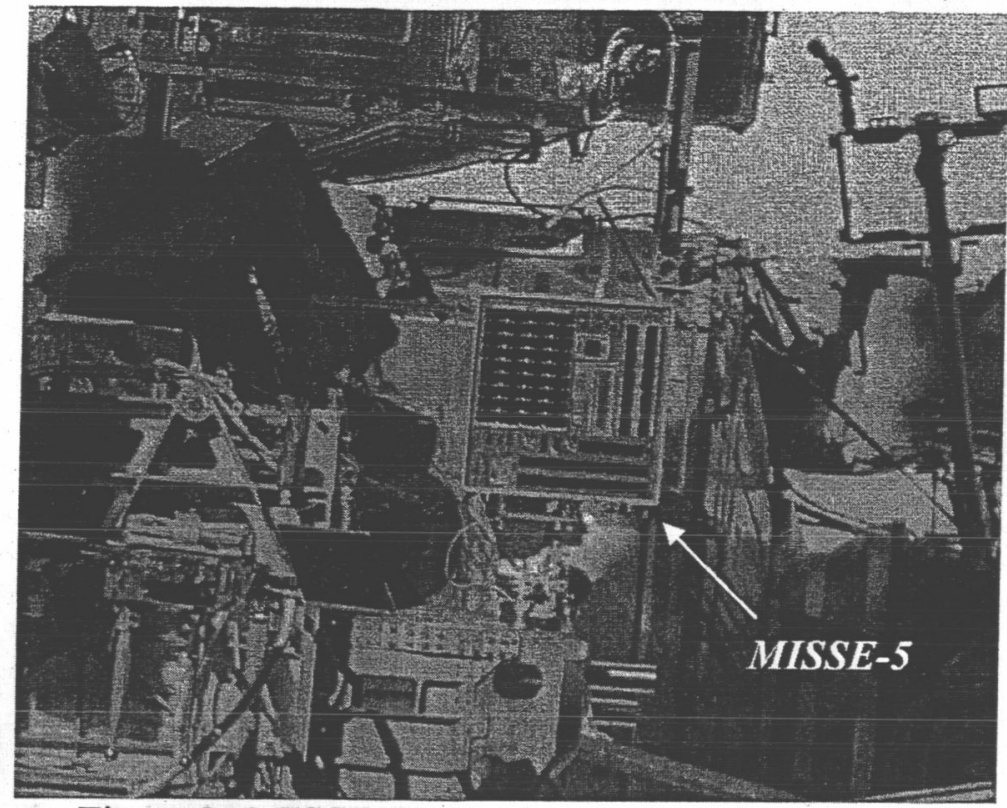

Figure 2. MISSE-5 deployed on ISS, August 2005.

Whenever possible, the flight experiment data is compared to ground simulations for data anchoring. Changes in mass, optical properties, and mechanical integrity are discussed. 